FEATURE

Rob Luckwell

\section{Office for National Statistics}

\section{SUMMARY}

This article describes the effects of rebasing the producer price index onto a $2005=100$ base year and briefly summarises the effects that rebasing has on the main headline output and input series of producer prices. The article shows the difference in weighting patterns of both the output and input series of producer prices between the new base year $(2005=100)$ and the previous base year $(2000=100)$. The article also shows a graphical comparison of index values of the main headline series as well as giving a background to producer prices.

\title{
Producer price index rebasing to $2005=100$
}

he producer price index (PPI) covers four main areas, as indicated in Table 1. The new PPI 2005 $=100$ data were published on 13 October 2008 . This article is intended to give some background information on the rebasing exercise and was released at the same time, which is consistent with the National Statistics Protocol on Release Practices.

\section{Overview to the changes to the PPI}

The PPI has been rebased onto 2005.

Rebasing is a five-yearly process for the PPI that updates the weights used to aggregate detailed PPI indices. Further details of the PPI structure and weighting are provided in the Appendix.

With effect from 2005, military products were excluded from the Products of the European Community (PRODCOM) list of questions. As a result, changes have been made to the framework for SIC 2960 (weapons and ammunition), 3511 (ships) and 3530 (aircraft and spacecraft). These changes have no effect on the overall structure of the PPI output series.

\section{Changes to the military series}

The decision to exclude military data from PRODCOM caused changes from 2005 to the PRODCOM list. However, PRODCOM decided to continue collecting military sales data but not within the existing question structure. Therefore, to continue collecting military sales, three new PRODCOM headings were created. As the PPI weights are based on home sales derived from PRODCOM sales, this meant that these changes had to be reflected in the PPI framework for the affected series. As a result, three new military indices have been created in the $2005=100$ rebased series to reflect the new PRODCOM questions. In addition, some indices that existed in the $2000=100$ series no longer exist in the $2005=100$ series or are included in the new military headings. A complete list of indices showing the different structure is available on request.

\section{Rebasing - updating the weights}

Updating the base year from the current 2000 to 2005 has led to some changes in weights. The weights at the higher levels have been derived using 2004 Input-Output tables as a proxy for 2005 weights. Current and revised weights for each division within the high net sector output (NSO) level are shown in Table 2.

Component weights at this level are based on Input-Output data. The largest differences in weights occur in the alcoholic beverages, clothing, printing and publishing, chemicals and motor vehicles divisions.

\section{Table 1}

Main types of PPI series

\begin{tabular}{lr}
\hline Description & Index \\
\hline Gross sector output (GSO) & $71 \times x x x x x x x$ \\
Net sector output (NSO) & $72 x x x x x x x x$ \\
Gross sector input (GSI) & $61 x x x x x x x x$ \\
Net sector input (NSI) & $62 x x x x x x x x$ \\
\hline
\end{tabular}


Table 2

\section{Current and revised weights: by division}

\begin{tabular}{lrr} 
& & Percentages \\
\hline Component description & 2000 weight & 2005 weight \\
\hline Food products excluding beverages & 15.0 & 14.2 \\
Alcoholic beverages & 9.3 & 6.1 \\
Mineral waters and soft drinks & 1.3 & 1.2 \\
Tobacco & 3.6 & 3.1 \\
Textiles & 3.1 & 3.1 \\
Wearing apparel; furs & & \\
Leather and leather products & 5.2 & 6.8 \\
Wood and products of wood and cork (except furniture), & 0.9 & 1.7 \\
articles of straw and plaiting materials & 0.7 & 1.1 \\
Pulp, paper and paper products & & \\
Printed matter and recorded media & 1.9 & 1.8 \\
& 7.0 & 5.1 \\
Petroleum & & \\
Chemicals, chemical products and man-made fibres & 9.1 & 7.8 \\
Rubber and plastic products & 5.7 & 2.7 \\
Other non-metallic mineral products & 2.7 & 2.8 \\
Base metals & 2.9 & 0.2 \\
& 0.2 & 2.2 \\
Fabricated metal products, except machinery and equipment & & 100.0 \\
Machinery and equipment n.e.c. & 3.3 & 6.2 \\
Office machinery and computers & 4.5 & 1.5 \\
Electrical machinery and apparatus n.e.c. & 1.4 & 1.3 \\
Radio, television and communication equipment and apparatus & 1.5 & 3.6 \\
Medical precision and optical instruments, watches and clocks & 2.9 & 2.3 \\
Motor vehicles, trailers and semi transport & & 8.9 \\
Other transport & 1.8 & 2.5 \\
Other manufactured products including recycling & 6.5 & 1.9 \\
Total & 6.8 & \\
\hline
\end{tabular}

\section{Figure 1}

\section{Effect of component weight changes to net sector output ${ }^{1}$ series}

Indices $(2005=100)$

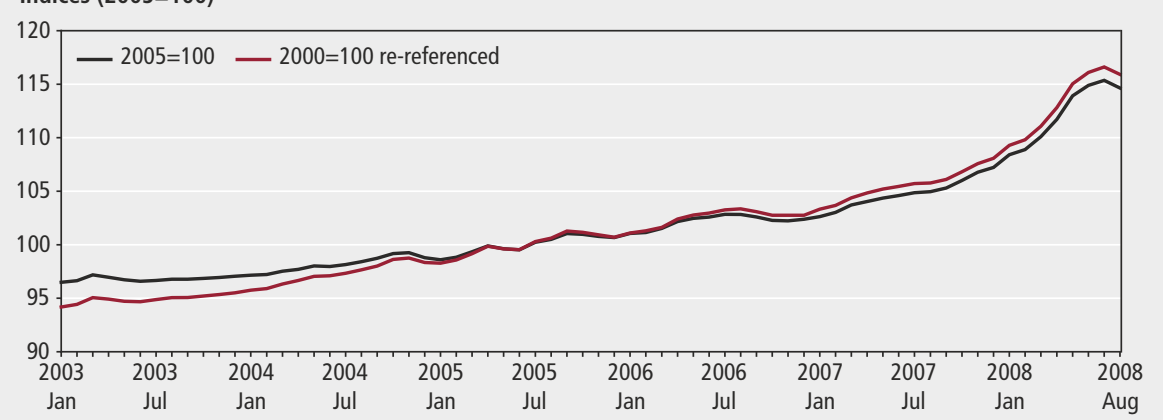

Note:

1 All manufacturing including duty.

Figure 2

\section{Contribution of major components to annual growth in net sector output series}

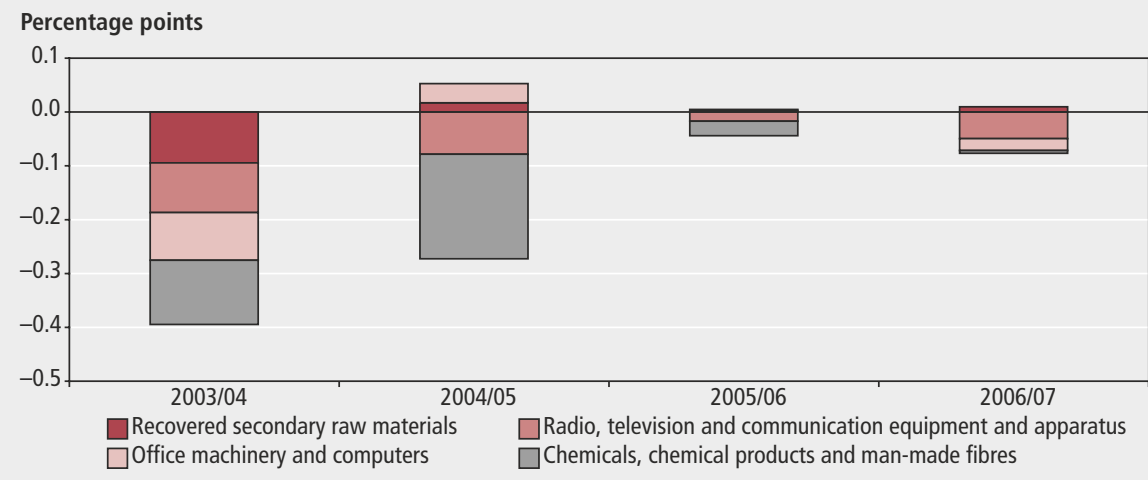

\section{Total effect on net sector output}

The effect of the component weight changes to the NSO series is illustrated in Figure 1. Here, the 2000-based series (re-referenced to $2005=100$ to aid comparison) is compared with the rebased series.

The largest differences are evident in the earlier periods, with differences of around two index points. After 2005, the differences are generally smaller, being around one index point or less. These differences are mainly due to the chemicals; computers; radio, television and communication equipment; and recycling sectors.

Figure 2 shows the contribution these components make to the annual growth in the NSO for the $2005=100$ series.

\section{Effect of updating the weights on the input series}

Component weights at the high net sector input (NSI) level are based on Input-Output data. Table 3 shows the commodity groups which make up the high-level NSI series and their respective weights. The largest differences in weight occur in crude oil, food, fuel and other imported parts and equipment divisions.

\section{Total effect on net sector input}

The effect of the component weight changes to the NSI series is illustrated in Figure 3.

Again, the 2000-based series (re-referenced to $2005=100$ to aid comparison) is compared with the rebased series.

The largest differences are evident in the earlier periods, with differences of around three index points. In 2004, the differences fall to around one index point, and up to April 2008 they are negligible, falling to less than half an index point. These differences are mainly due to the imported chemicals, home-produced food, imported metals and other home-produced materials sectors.

\section{Conclusion}

The overall change to the headline output and input PPIs reflects broadly the same patterns as the $2000=100$ series. 
Table 3

Current and revised weights: by commodity group

\begin{tabular}{lrr} 
& & Percentages \\
\hline Description & 2000 weight & 2005 weight \\
\hline Home-produced and imported crude oil & 12.4 & 19.0 \\
Imported food & 4.4 & 5.5 \\
Other home-produced & 1.5 & 2.9 \\
Imported metals & 7.0 & 6.7 \\
Imported chemicals & 13.2 & 11.4 \\
& & 8.8 \\
Fuel including climate change levy & 6.9 & 11.1 \\
Home-produced food & 7.8 & 11.2 \\
Other import commodities & 12.8 & 23.4 \\
Other imports - parts and equipment & 34.0 & 100.0 \\
Total & 100.0 & \\
\hline
\end{tabular}

Figure 3

Effect of component weight changes to net sector input ${ }^{1}$ series

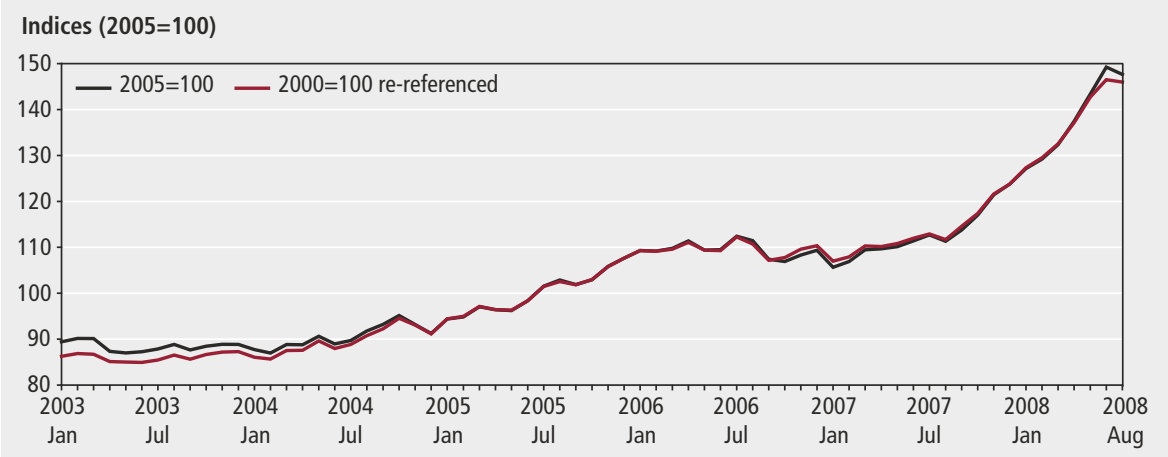

Note:

1 Materials and fuel purchased including climate change levy.

\section{CONTACT}

(囚)elmr@ons.gsi.gov.uk 


\section{APPENDIX}

\section{Background to producer prices}

The PPI measures the change in prices of goods bought and sold by manufacturers. Overall, there are four types of PPI series produced:

- gross sector output (GSO)

- net sector output (NSO)

- gross sector input (GSI), and

- net sector input (NSI)

The differences between output and input prices are:

- output prices - measure the change in price of goods sold by UK manufacturers

- input prices - measure the change in price of goods bought by UK manufacturers for use in the manufacturing process

The differences between net and gross sector are:

- net sector - the weights used to calculate these exclude transactions between companies classified to the same sector, for example, the value of an electronic component manufacturer's sales to a car manufacturer would be excluded from the weights (thereby reflecting the value of sales to purchasers outside the manufacturing sector)

- gross sector - all transactions are included when deriving the weights, including sales within the same sector

The same basic price information is used to feed into each of these four types of PPI series. The difference between the various types lies in the weights that are applied to combine the low-level series to form these higher-level indices and which low-level series are combined to form the high-level indices. The headline series produced in the PPI First Release is the NSO allmanufacturing series including duty.

\section{Price data}

Around 6,750 price quotes are collected each month, together with some prices from administrative sources such as trade publications and other government departments. Output PPIs are calculated at a fairly detailed product group (six-digit) level, with the products that fall into each PPI defined by the European Classification of Products by Activity (CPA), which in turn is based on the current 2003 Standard Industrial Classification. Indices produced for 1,270 detailed product groups (sixdigit) are then grouped together using the 'family tree' structure of the CPA to produce 237 industry (four-digit) level series. The industry-level series are then grouped to give 24 division-level (two-digit) indices, which in turn are grouped into the allmanufacturing index. An example of this structure is provided in Figure A1.

\section{Index weights}

The high-level all-manufacturing series are generally structured in the same way. It is easiest to explain the structure for the GSO excluding duty series. Initially, the prices supplied by each contributor are compared with the average price of the same item in the base period, to form a price relative. The price relatives are then weighted together with other products of a similar description to form the six-digit product index. The weights are derived based on the value of the PRODCOM sales (total sales figure obtained from the Products of the European Community survey). The six-digit product groups are then grouped together with the other products of a similar nature to produce the industry indices. In turn, these industries are weighted together to form their retrospective divisional indices. Finally, weighting together all the divisional series then produces the GSO allmanufacturing index.

Indices from product level to divisional level are produced on a gross sector basis. At the all-manufacturing level, output indices are produced on a gross and net sector basis. To calculate the NSO series, the same method is used to produce indices from the product level to generally divisional level as is used for the GSO series. To combine the division-level indices to produce the all-manufacturing NSO series, Input-Output data are used in place of PRODCOM (and export) data to provide index-weighting patterns. Unlike PRODCOM data, which provide only a total product sales value, Input-Output data allow a split in sales to be made within and outside the manufacturing sector, enabling sales to the manufacturing sector to be excluded from the NSO weights.

The NSI series is calculated from import and GSO indices which are calculated up to input/output group level using similar methods to those described above. These series are then weighted together using input/output domestic and import data, removing sales and imports to the manufacturing sector, in the same way as for the NSO series.

\section{Figure A1 \\ Example of family tree structure}

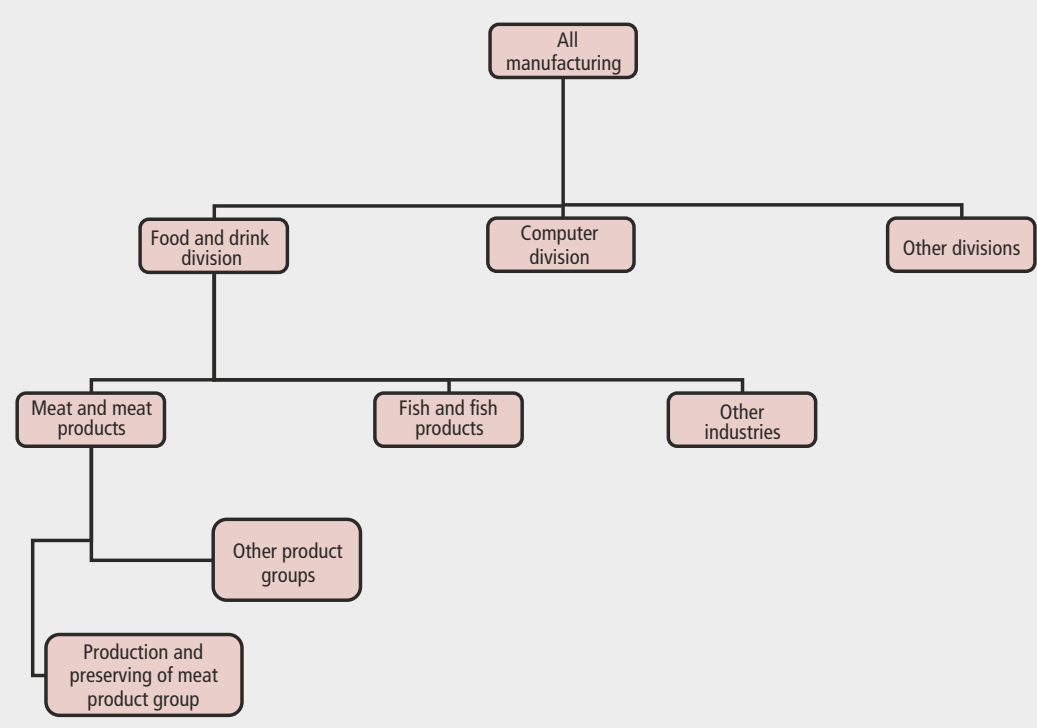

